\title{
A BUMP IN THE ROAD
}

\author{
RICARDO MENA \\ https://orcid.org/0000-0002-1185-9510 \\ UNAM - Instituto de Investigaciones Filosóficas \\ Department of Philosophy \\ Coyoacan - Ciudad de México \\ México \\ rmena@filosoficas.unam.mx
}

\section{Article info}

CDD: 401

Received: 17.08.2020; Revised: 10.09.2020; Accepted: 16.09.2020

https://doi.org/10.1590/0100-6045.2020.V43N4.RM

\section{Keywords}

Reference

Bump in the Road

\begin{abstract}
Roads to Reference offers a highly valuable contribution to the theory of reference. The arguments in this book are quite convincing and the overall picture presented in it is quite attractive. In what follows I would like to present some critical comments regarding the first chapter of the book, Demonstratives and Conflicting Intentions.
\end{abstract}

In this contribution I would like to focus on what the book has to say about demonstrative reference. In Roads to Reference Gomez-Torrente criticises theories according to which the semantic conventions of demonstratives determine necessary and sufficient conditions for reference. Needless to say, most theories in the market are targeted by Gomez-Torrente's criticisms. Once the terrain is clear, the book puts forward a novel theory of demonstrative reference. The key feature of this theory is that, according to it, the semantic conventions governing demonstrative reference only provide sufficient conditions for reference 
and reference failure. Given this feature, Gomez-Torrente's theory manages to avoid the kind of problem had by rival theories while still being able to provide a robust theory of demonstrative reference.

In what follows I will briefly present Gomez-Torrente's criticism of theories that attempt to provide necessary and sufficient conditions for demonstrative reference. Then I will sketch Gomez-Torrente's novel view and explain in what sense it's an improvement over other theories in the market: only offering sufficient conditions can be fruitful. Finally, I will put forward a theory that offers necessary and sufficient conditions for demonstrative reference and that it's not subject to Gomez-Torrente's criticism. The point of this is to suggest that there is a bump in the road: perhaps the theory of demonstrative reference offered in Roads to Reference was a bit hasty in departing from an attempt to specify necessary and sufficient conditions for demonstrative reference.

Here's a simple and suggestive theory of demonstrative reference: ${ }^{1}$

(Simple Intention) A use of a demonstrative refers to an object $\mathbf{o}$ iff $\mathbf{o}$ is the thing that the utterer intends to refer to with his/her use. (RR, p...)

Simple Intention works very well in simple cases. If I intend to refer to Nina with my use of "that", then my use of "that" refers to Nina. If I don't intend to refer to Rulfo

${ }^{1}$ One could argue that Kaplan (1989, p.582) held, or at the very least he seriously considered, something along the lines of this theory. 
with my use of "that", my use of "that" doesn't refer to Rulfo. All this seems to be in order. However, things aren't always that simple. As Gomez-Torrente and others have pointed out, there are conflicting intentions cases: these are cases where the speaker has two (or more) referential intentions that, unfortunately, pick out different things. These cases can be problematic for Simple Intention because in them there is no single $\mathbf{o}$ that is the $\mathbf{o}$ that the speaker intends to refer to with her use of the demonstrative and intuition doesn't always predict that's the right result.

Consider the following Gomez-Torrente case. At a distance you can see some students playing football. One of them, the one wearing a yellow t-shirt, stands out as a particularly good player. You think, wrongly, that he is your philosophy of language student. Pointing at him you say, "That's a really good player". You have the intention to refer to the player with the yellow shirt and also you have the intention to refer to your philosophy of language student. You have conflicting referential intentions. Simple Intention predicts that in this case you didn't manage to secure a referent for your demonstrative use. However, GómezTorrente's intuition is that you managed to refer to the player with the yellow shirt: the one you pointed at. I think GomezTorrente's intuition is correct.

Now consider Kaplan's (1978) example. For many years Kaplan has had a picture of Carnap behind his office chair. Unbeknownst to him that picture has been switched for a picture of Spiro Agnew. Kaplan is sitting at his office chair and, without turning around, he points at the picture behind him and says: "That is the picture of one of the greatest philosophers of the 20th century". With his use of the demonstrative he intends to refer to the picture of Carnap, but he also intends to refer to the picture that is behind him. He has two conflicting referential intentions: the picture of Carnap and the picture that's behind him are two different 
things. Simple Intention predicts that in this case there is no reference, since there is no o that is the thing that Kaplan intends to refer to with his use of the demonstrative. According to Gómez-Torrente, it is far from clear that this is the correct prediction.

$[\mathrm{M}] \mathrm{y}$ impression is that it is unclear whether that use refers to the picture of Agnew, to the picture of Carnap, or else lacks a reference: as far as I can tell, it is unclear whether the conventions determining reference or reference failure for uses of "that" imply that that use has a particular picture as its reference, or that it lacks a reference. I also take this unclarity to be a prima facie indicator that the matter may be left indeterminate by the conventions fixing the reference of demonstratives or determining when they fail to refer. (Gómez-Torrente, 2019, p.40)

And later on he adds:

And again, more importantly, I don't think that we would judge incompetent a speaker who did not judge it appropriate to issue a definite verdict of reference or reference failure in this case.(Gómez-Torrente, 2019, p.43)

There are two points I would like to focus on from these passages. (a), there is the unclarity intuition: it is unclear whether the use of the demonstrative refers to the picture of Carnap or Agnew, and (b), if we wouldn't judge as incompetent a speaker who didn't judge it appropriate to issue a definite verdict of reference or reference failure, that's a good tell, according to Gómez-Torrente, that the semantic 
conventions of demonstratives do not determine a particular referent in this kind of case: if they did, we would judge such a speaker as incompetent.

Gomez-Torrente's observations apply, after adequate modifications, against what he calls Overriding Theories: theories that include, among their necessary and sufficient conditions for reference, conditions under which some conflicting intentions get overridden, allowing for the referential intention that has not been overridden to determine reference. I agree with Gomez-Torrrente: overriding theories should be rejected. So I won't focus on them any longer.

If Gomez-Torrente's two points ((a) and (b)) are sound, then theories that offer necessary and sufficient conditions for demonstrative reference are in trouble. As a result, Gómez-Torrente offers a novel theory of demonstrative reference: one according to which the linguistic conventions governing demonstrative reference only offer sufficient conditions for reference and reference failure. The details are plenty. For now it suffice to say that his theory offers the right predictions in clear cases of demonstrative reference and reference failure, and in unclear cases the theory predicts that it is semantically indeterminate whether there is reference. The first of Gómez-Torrente's points, (a), can be easily accounted for by his theory, given that unclarity and indeterminacy go hand in hand: it is unclear whether there is reference, because it is indeterminate whether there is reference. The second point, (b), is also easily accounted for by his theory: we wouldn't judge such a speaker as incometent, because refraining from offering a reference verdict is a correct attitude, given that it is indeterminate whether there is reference in those cases.

I think Gómez-Torrente's two points are quite sound, but only if we confront conflicting intentions cases with the following presupposition in mind: at most, there can only be 
one demonstrative referent (either, say, the picture of Carnap or the picture of Agnew). If we look at Kaplan's case, and we ask ourselves: given that there is at most one referent, which one is it?, it is exceedingly natural to judge the situation as unclear, in line with Gómez-Torrente's intuitions. However, if we have reasons to drop that presupposition, if it is an open theoretical option that, somehow, demonstratives have two referents in conflicting intentions cases, then it is less obvious that the unclarity judgment is justified. In what follows I would like to make sense of the idea that in conflicting intentions cases demonstratives have two (or more) referents. Furthermore, I will argue that this view can claim that the linguistic conventions governing demonstrative reference offer necessary and sufficient condition for reference and reference failure. Then I will argue that this view can account for our intuitions regarding demonstrative reference quite well. The goal of doing all this is to point out that Gómez-Torrente's departure from theories offering necessary and sufficient conditions for demonstrative reference is, perhaps, a bit hasty.

Why is it so common to think that demonstratives cannot have more than one referent per use? It is quite natural to think that this restriction is part of their meaning: demonstratives are, after all, singular terms. ${ }^{2}$ Perhaps that is

2 Thanks to Mario Gómez-Torrente for suggesting this. It should be pointed out that Nowak (2019) challenges this view. According to him, demonstratives are variables, and the role of context is to initiate their variable assignments, where it is perfectly possible for a context to initiate more than one variable assignment for a demonstrative. Nowak's view challenges a commonly accepted view. In my view one could perfectly well take advantage of most of Nowak's theory and claim that what goes on in conflicting intentions cases is that there are two or more simultaneous contexts each of them initiating different variable assignments. 
why Speaks (2017) claims that the two referents approach is obviously not an option as a solution to conflicting intentions cases. Of course, this is not to say that demonstratives can't have two different referents relative to two different kaplanian contexts: one referent per kaplanian context (just context, from now on). There is nothing in the meaning of demonstratives preventing them from having different referents in different contexts. What I would like to suggest is that in conflicting intention cases there are two simultaneous contexts: one for each referential intention. Thus, in conflicting intentions cases, with a single utterance, a speaker can manage to refer to two different objects, relative to different (but simultaneous) contexts.

What we have to do now is make sense of the idea that in conflicting intentions cases there are two simultaneous contexts at play. That sometimes two simultaneous contexts are required to make sense of what happens in a given conversation is not a strange proposition. Suppose we are having a conversation with Celeste and I've been talking for some time about the intricacies of my favorite chess opening. At some point you and Celeste exclaim at the same time: "I'm so bored!". Presumably, to make sense of what goes on at this point in the conversation, we need two contexts: one where you are the speaker and a different one where Celeste is the speaker. When there are two simultaneous speakers, it's not possible--at least not without fancy technical tricks-to assign a referent to both instances of "I" relative to a single context.

Now, here is an example closer to what I need. Suppose

Siegel (2002) also has a view where a single demonstrative can have two referents in one context (thanks to Matheus Valente for pointing this out). I also think Siegel could perfectly claim, as I do, that there are two simultaneous contexts at play. 
you and Celeste can't find your respective books, and I know it. We are positioned in such a way that you can only see the left hand side of my body and Celeste can only see the right hand side of my body. Simultaneously I point at your book with my left hand and to Celeste's book with my right hand, while saying "That's your book". 3 This example resembles a conflicting intentions case: I have two referential intentions each one aiming at different objects. ${ }^{4}$ However, it seems clear that in this case I manage to refer to both books: it's not an open question how you and Celeste should interpret my utterance. I think that we can make sense of this example is by claiming that in this case there are two different simultaneous contexts at play: one relative to which "that" refers to your book and another relative to which the same instance of "that" refers to Celeste's book. Of course, it has to be the case that one of the contexts is only sensitive to one of the referential intentions, while the other context is only sensitive to the other referential intention (that's the point of having two contexts to begin with). We can accept Simple Intention relativized to each context, thereby having a theory that offers necessary and sufficient conditions for reference (relative to a context)..$^{5}$ Notice how the alternative

${ }^{3}$ I think that Jeff King has a similar example, but I'm not sure what he uses it for.

${ }^{4}$ I'm not claiming that it is a conflicting intentions case. It may very well be, but it is enough for my purposes if it's similar to a conflicting intentions case.

5 I'm not confident that Simple Intention is all we need for all cases, what matters is that there are more than one simultaneous context at play. So, perhaps there are some cases where pointing takes priority over referential intention (Stojnic, et al., 2013). The theory I'm sketching here can be adapted to make justice to those intuitions. 
treatments of this kind of case are not quite appealing: a single context relative to which "that" has two referents or a single utterance counting as two different ones (so, there are two different instances of "that") ${ }^{6}$.

We can treat standard conflicting cases in a similar way. In the first example, your utterance of "That's a good player" requires two context (one per referential intention). Relative to each context, the demonstrative has a different referent. The same thing can be said about Kaplan's example. Now we have to make sure there is a way of looking at these results that is fairly intuitive. For now I would rest content if there is a way of capturing something in the ballpark of GómezTorrente's (a) and (b) intuitions.

I grant that there are situations where in the Kaplan case it would be normal for unclarity to arise, but that depends on how much the audience knows about the particular case. Also, I think it's up for grabs what's the unclarity about. First I will consider the unclarity claim from the perspective of the audience, and then I will do it from the perspective of language theoreticians. Suppose the audience doesn't know much about Carnap, Agnew, what Kaplan thinks about both of them, and what has happened to their pictures. Then it would be normal for the audience to be unclear about how to understand Kaplan's utterance of "That's the picture of one of the greatest philosophers of the 20th century". On Gómez-Torrente's view, this is a case of unclarity about whether there is reference. In my view it is a case of unclarity about which of the two propositions Kaplan expressed (in different, but simultaneous contexts) to accept: Kaplan referred to both the picture of Carnap and Agnew, so he

\footnotetext{
${ }^{6}$ If one opts for this second alternative, one would still have the burden of explaining how a single context can assign referents to these instances of "that". Perhaps that can be done, but I don't see any advantage for going that way rather than the way I propose.
} 
expressed two propositions. This is unclarity about which is the proposition that Kapan didn't want to express: or, if you like, it is unclarity about which referential intention Kaplan didn't mean to have. This is unclarity that it's not based on semantic indeterminacy, it is unclarity based on something much more mundane: the audience simply doesn't know enough about the situation at hand.

Notice that if the audience is well informed, there is less temptation to claim that the situation is unclear: If the audience knows what Kaplan thinks about both Carnap and Agnew, and they know that unbeknownst to Kaplan the pictures have been swapped, then it is fairly clear that the audience should take Kaplan to be referring to the picture of Carnap. ${ }^{7}$ The audience would also be in a position to dismiss Kaplan's reference to the picture of Agnew as a case of unintended reference: something they can simply ignore. So Kaplan refers to both pictures (in different contexts) and he expresses the two related propositions. An audience that knows enough about the situation at hand would be in a position to simply ignore the proposition about Agnew as something Kaplan didn't mean to express, even though he did.

We, as theoreticians, are well informed about this case. Once the possibility that Kaplan referred to both pictures (relative to different but simultaneous contexts) is open, I feel less tempted to claim there is unclarity. Rather, it seems quite clear that Kaplan meant to refer to Carnap's picture, that he managed to do so, that that reference to Angnew's picture was something unintended. As theoreticians we should claim unclarity, as Gómez-Torrente does, only if we are assuming that, in cases of conflicting intentions, at most there can be one referent. But, I hope at least I have made plausible the claim that we should drop that assumption.

${ }^{7}$ For similar intuitions about this see (King, 2013). 
Now, let me say something about the second intuition. In the case where the audience has enough ignorance about Kaplan's case, yes, we wouldn't judge incompetent a speaker who suspends judgment. In Gómez-Torrente's view the speaker in question is one that suspends judgement about whether there is a referent. In my view the speaker suspends judgment about which picture Kaplan means to refer to. Of course, both kinds of suspension of judgment are quite similar and I think it would be a mistake to think that the intuitions we initially have about Kaplan's case clearly discern between them. We should seriously consider that the proper way to account for the intuition we have about Kaplan's case is in the way I have suggested. However, in a case where the audience is fully informed, I think we would judge as incompetent someone who refrains from judging that Kaplan meant to refer to Carnap's picture and not to Agnew's.

The "That's a really good player" case can also be easily accounted for by the theory I'm putting forward here. Relative to different, but simultaneous contexts, you managed to refer to both the player you are pointing at and to your philosophy of language student. This is a case where your audience should interpret you as meaning to refer to the player you are pointing at, and, in case the audience somehow has access to your other referential intention (the one picking out your student) they should take it as mistaken, thereby ignoring your reference to the philosophy of language student.

\section{REFERENCES}

Gómez-Torrente, M. (2019). Roads to Reference: An Essay on Reference Fixing in Natural Language. Oxford University Press. 
Kaplan, D. (1978). Dthat. In P. French, T. Uehling, \& H. Wettstein (Eds.) Contemporary Perspectives in the Philosophy of Language, (pp. 383-400). Minneapolis: University of Minnesota Press.

Kaplan, D. (1989), "Demonstratives", in J. Almong, J.Perry, and H. Wettstein (eds.), Themes from Kaplan, Oxford University Press, Oxford, 1989, 481-563.

King, J. C. (2013), "Supplementives, the Coordination Account, and Conflicting Intentions", Philosophical Perspectives 27, 288-311.

Nowak, E. (2019). No context, no content, no problem. Mind \& Language.

Siegel, S. (2002). The Role of Perception in Demonstrative Reference. Philosophers' Imprint,

2(1), 1-21.

Speaks, J. (2017), "A puzzle about Demonstratives and Semantic Competence", Philosophical Studies, 174, 709-34.

Stojnic, U., Stone, M., \& Lepore, E. (2013). Deixis (Even without Pointing). Philosophical Perspectives, 27, 502-525.

BY

Manuscrito - Rev. Int. Fil. Campinas, v. 43, n. 4, pp. 177-188, Oct.-Dec. 2020. 